\title{
Laughter Yoga versus group exercise program in elderly depressed women: a randomized controlled trial
}

\author{
Mahvash Shahidi $^{1}$, Ali Mojtahed ${ }^{2}$, Amirhossein Modabbernia ${ }^{2}$, Mohammad Mojtahed $^{2}$, Abdollah Shafiabady ${ }^{1}$, \\ Ali Delavar ${ }^{3}$ and Habib Honari ${ }^{3}$ \\ ${ }^{1}$ Department of Counseling, School of Psychology \& Training Sciences, Allameh Tabatabai University, Tehran, Iran \\ ${ }^{2}$ Student Research Office, Research Deputy, Imam Khomeini Hospital Complex, Iran \\ ${ }^{3}$ Faculty of Psychology, Allameh Tabatabai University, Tehran, Iran \\ Correspondence to: M. Shahidi, PhD, E-mail: Mahvash.shahidi@gmail.com \\ ${ }^{\dagger}$ Assistant Professor, PhD of Counselling.
}

Background: Laughter Yoga founded by M. Kataria is a combination of unconditioned laughter and yogic breathing. Its effect on mental and physical aspects of healthy individuals was shown to be beneficial. Objective: The objective of this study was to compare the effectiveness of Kataria's Laughter Yoga and group exercise therapy in decreasing depression and increasing life satisfaction in older adult women of a cultural community of Tehran, Iran.

Methods: Seventy depressed old women who were members of a cultural community of Tehran were chosen by Geriatric depression scale (score > 10). After completion of Life Satisfaction Scale pre-test and demographic questionnaire, subjects were randomized into three groups of laughter therapy, exercise therapy, and control. Subsequently, depression post-test and life satisfaction post-test were done for all three groups. The data were analyzed using analysis of covariance and Bonferroni's correction.

Results: Sixty subjects completed the study. The analysis revealed a significant difference in decrease in depression scores of both Laughter Yoga and exercise therapy group in comparison to control group $(p<0.001$ and $p<0.01$, respectively). There was no significant difference between Laughter Yoga and exercise therapy groups. The increase in life satisfaction of Laughter Yoga group showed a significant difference in comparison with control group $(p<0.001)$. No significant difference was found between exercise therapy and either control or Laughter Yoga group.

Conclusion: Our findings showed that Laughter Yoga is at least as effective as group exercise program in improvement of depression and life satisfaction of elderly depressed women. Copyright (C) 2010 John Wiley \& Sons, Ltd.

Key words: laughter therapy; laughter yoga; exercise therapy; depression; life satisfaction; older women History: Received 13 January 2010; Accepted 16 April 2010; Published online in Wiley Online Library (wileyonlinelibrary.com).

DOI: $10.1002 /$ gps. 2545

\section{Introduction}

Despite emergence of new diagnostic and therapeutic strategies, late life depression-defined as depression after age 65-continued to show unfavorable outcomes (Alexopoulos, 2005). Although pharmacological treatment has an important role in the treatment plan, psychotherapeutic interventions as well as complementary and alternative medicine are also important particularly in older who have co-morbid medical conditions and may experience more side effects with pharmacological treatment because of drug interactions and altered drug metabolism (Noyes, 1997; Noble, 2003).

One of the alternative modalities, which were developed recently by $\operatorname{Dr}$ M. Kataria, an Indian physician, is a kind of laughter exercise named as Laughter Yoga. Laughter Yoga combines uncondi- 
tional laughter with yogic breathing. In this activity, one laughs without relying on humor, jokes, or comedy and laughter is simulated as a body exercise in a group. Kataria believes that both fake and real laughter has the same effect on the body (Kataria, 2005). However, as stated in a review on humor and laughter, number of scientific works on laughter and humor are limited (Bennett and Lengacher, 2008). Nevertheless, many of existing works showed the beneficial effects of laughter on different body systems such as muscle relaxation and changes in immunological, hormonal, and mental parameters (Bennett and Lengacher, 2008). In the case of Laughter Yoga there is even more lack of methodologically robust data. There are only two articles in which effects of Laughter Yoga were assessed on healthy individuals, both of which showed promising results (Beckman et al., 2007; Nagendra et al., 2007). Till date, no work was done on the effects of this alternative treatment on mental illness, particularly depressive disorder.

We conducted the present study to compare the effect of this method with a better-known alternative modality: the exercise therapy. A recent systematic review showed the beneficial effect of exercise (in general) on the treatment of diagnosed depressive disorder (Mead et al., 2009). The same finding was shown in a review by Palmer about the effect of different kinds of exercise on the treatment of late life depression (Palmer, 2005).

This study was designed to assess the real efficacy of Laughter Yoga in the treatment of late life depression. As mentioned above, we chose exercise therapy as a well-known alternative for comparison, and to strengthen our findings, we also included a control group. We chose elderly population because of high prevalence of co-morbid conditions and thus potentially more exposure to drug adverse effects and we selected women both because they are a more susceptible population in our country (Mohammadi et al., 2005) and were more accessible.

\section{Methods}

\section{Participants}

Participants were aged depressed women with an age range of 60-80 years of age. They were selected from members of a cultural community center for older women named 'Kanoone Jahandidegan' which was located in District 13 and was chosen randomly out of 22 districts of Tehran, capital of Iran. The center is a place for spending leisure time designed for older individuals. The calculated sample size was 60 , and with a predicted drop out rate of $15 \%, 70$ old depressed women were chosen out of 500 members of this district using geriatric depression scale (GDS). Participants with the GDS of 10 or more were included. They were randomly assigned to Laughter Yoga $(n=23)$, exercise therapy $(n=23)$, and control groups $(n=24)$. The study was approved by the ethical committee of University and the individuals gave informed consent to participate in the experiments.

\section{Assessment instruments}

Three instruments were used for assessment of participants.

(1) Baseline characteristics questionnaire: this questionnaire assessed age, level of education, occupation, number of children, and living status of individuals and was designed by the researcher.

(2) Yesavage Geriatric depression scale (GDS): this scale contains 30 yes or no questions and divides individuals into without depression (0-9), moderately depressed (10-19), and severely depressed (20 and more) ones. This questionnaire was validated in 30 Iranian patients; using Spearman Brown formula the validity was calculated $96 \%$. Correlation with Hamilton scale and Beck inventory were $r=0.84$ and 0.73 , respectively and Test retest reliability was 0.85 .

(3) Diener life satisfaction scale (LSS): this is a fiveitem seven-degree Likert type scale, which was designed to assess life pleasure in general. Both validity and reliability have been shown to be acceptable. Cronbach's $\alpha$ coefficient is 0.87 and correlation with other life satisfaction inventories is moderate to high.

Intervention

Two kinds of intervention were used for participants.

(1) Laughter Yoga: As mentioned above, this is a method founded by M. Kataria in 1995. Laughter Yoga was performed in 10 sessions by one of the researchers who were trained in Laughter Yoga. Each session consisted of:

- A brief talk about something delightful like national and religious ceremonies, having positive attitudes to everyday life affairs, living 
in the 'present time', having activity, working, etc. This stage acted as a mental preparation for laughter exercise.

- Clapping hands parallel to each other for full finger-to-finger and palm-to-palm contact; Kataria explained this stage stimulate acupressure points in hands to increase energy levels. This is accompanied by rhythm i.e., 1, 2, 3.

- Moving hands up and down and swinging from side to side, with corresponding movements of the upper and lower extremities.

- A simple chant is added to the clapping, normally $\mathrm{HO}, \mathrm{HO}, \mathrm{HA}-\mathrm{HA}-\mathrm{HA}$. Kataria believes these chants worked as heavy exhalations that come from the abdomen, to stimulate diaphragmatic breathing.

- Adding harmonic movements to boost feelings of happiness and joy.

- Having gibberish that is languages of sounds without meaning like what children do when playing. Gibberish may be used as a warm up exercise in Laughter Yoga, to help individuals to reduce inhibitions and shyness.

- Laughter exercises are interspersed with deep breathing exercises to bring physical and mental relaxation.

- One of the objectives of Laughter Yoga is to encourage childlike playfulness that helps individuals to laugh without reason. A happy chant to use after a laughter exercise: very good (clap forward).

- Performing Laughter Yoga techniques, each for 30-45 s following by clapping and hands and saying HO HO HA-HA-HA and two deep breaths. These techniques include: hearty laugh, silent laugh with mouth wide open, jumping laugh with mouth closed, medium laugh, cocktail laugh, arm swinging laugh, and one-meter laugh (see 'Laugh for no reason' by M Kataria for more details').

- In the end of each session, each participant shouts 'I am the happiest person in the world', then claps hands and looks at others and laughs.

(2) Exercise therapy: Ten sessions of aerobic group exercise program including jogging and stretching exercise were used for this group. Time of each session was about $30 \mathrm{~min}$ and each session was different from the others in the time and intensity of each exercise and individuals ended with cooling down in about $5 \mathrm{~min}$. Group program was used because it is more effective than individual exercise program. Besides, by using this program we could match two groups in this regard (Timonen et al., 2002).

\section{Data analysis}

Data were analyzed using SPSS version 15.00 for Windows. Descriptive statistics were reported in tables and as mean \pm standard deviation or frequency and percentage. Main outcomes were presented as box plot graphs. Analysis of covariance was used for controlling the possible effect of pre-test scores. Bonferroni's test was used for multiple comparisons of scores among study groups. $p$ value of less than 0.05 was considered significant.

\section{Results}

\section{Sample characteristics}

A total of 60 individuals aged $60-80($ mean $=66.56)$ completed the study. Table 1 presents the main characteristics of each group.

\section{Changes in depression scores}

We found that individuals in both laughter therapy and exercise therapy group showed significant improvement in their GDS scores (Table 2, Figure 1) when Bonferroni's correction was used for multiple comparisons between groups $(p<0.001$ for laughter therapy $v s$. control group and $p<0.01$ for exercise therapy vs. control group). There was no significant difference between two experimental groups $(p=0.4)$ (Table 3). To control the effect of pre-test on post-test scores we used analysis of covariance (ANCOVA) and showed significant difference among the means of the three groups (Table 4).

\section{Changes in life satisfaction scores}

Only subjects in Laughter Yoga group showed significant improvement in their LSS scores compared with controls (Table 2) $(p<0.001$ after Bonferroni's correction). There was no significant difference in the LSS scores between exercise therapy and control group (Table 3) $(p=0.1)$. Although in a student sample $t$ test analysis significant difference was found between Laughter Yoga and exercise therapy group $(p=0.04)$, this was not true when a Bonferroni's correction was carried out $(p=0.2)$. Again ANCOVA was performed to control for pre-test scores effect and showed significant difference between means of the three groups (Table 4). 
Table 1 Baseline characteristics of individuals

\begin{tabular}{|c|c|c|c|}
\hline Characteristics & $\begin{array}{l}\text { Laughter therapy } \\
\qquad(n=20)\end{array}$ & $\begin{array}{l}\text { Exercise therapy } \\
\qquad(n=20)\end{array}$ & $\begin{array}{l}\text { Control } \\
(n=20)\end{array}$ \\
\hline Age (mean $\pm S D)$ & $65.5 \pm 4.8$ & $65.7 \pm 4.2$ & $68.4 \pm 6.3$ \\
\hline \multicolumn{4}{|l|}{ Marital status } \\
\hline Single & $0(0 \%)$ & $0(0 \%)$ & $0(0 \%)$ \\
\hline Married & $11(55 \%)$ & $9(45 \%)$ & $8(40 \%)$ \\
\hline Divorced & $2(10 \%)$ & $0(0 \%)$ & $1(5 \%)$ \\
\hline Widow & $7(35 \%)$ & $11(55 \%)$ & $11(55 \%)$ \\
\hline \multicolumn{4}{|l|}{ Level of education } \\
\hline Illiterate & $1(5 \%)$ & $4(20 \%)$ & $3(15 \%)$ \\
\hline Before diploma & $13(65 \%)$ & $14(70 \%)$ & $15(75 \%)$ \\
\hline Diploma & $5(25 \%)$ & $2(10 \%)$ & $2(10 \%)$ \\
\hline After diploma & $1(5 \%)$ & $0(0 \%)$ & $0(0 \%)$ \\
\hline \multicolumn{4}{|l|}{ Occupation } \\
\hline Working & $4(20 \%)$ & $2(10 \%)$ & $2(10 \%)$ \\
\hline Retired & $0(0 \%)$ & $1(5 \%)$ & $0(0 \%)$ \\
\hline Housewife & $16(80 \%)$ & $17(85 \%)$ & $18(90 \%)$ \\
\hline \multicolumn{4}{|l|}{ Number of children } \\
\hline $0-2$ & $4(20 \%)$ & $5(25 \%)$ & $7(35 \%)$ \\
\hline $3-5$ & $13(65 \%)$ & $11(55 \%)$ & $8(40 \%)$ \\
\hline 6 or more & $3(15 \%)$ & $4(20 \%)$ & $5(25 \%)$ \\
\hline \multicolumn{4}{|l|}{ Living situation } \\
\hline Living alone & $5(25 \%)$ & $4(20 \%)$ & $7(35 \%)$ \\
\hline Living with spouse or children & $15(75 \%)$ & $16(80 \%)$ & $13(65 \%)$ \\
\hline
\end{tabular}

Table 2 Pre and post-test scores for Geriatric depression scale and life satisfaction scale in groups

\begin{tabular}{lccc}
\hline Tests & Laughter therapy $(n=20)$ & Exercise therapy $(n=20)$ & Control $(n=20)$ \\
\hline Geriatric depression scale & & & $15.2 \pm 3.9$ \\
Pre-test (mean \pm SD) & $16.0 \pm 5.3$ & $15.3 \pm 5.4$ & $15.2 \pm 6.1$ \\
Post-test (mean \pm SD) & $10.0 \pm 6.9$ & $11.1 \pm 6.2$ & $20.2 \pm 6.2$ \\
Life satisfaction scale & $19.2 \pm 4.1$ & $21.5 \pm 6.8$ & $20.0 \pm 5.1$ \\
Pre-test (mean \pm SD) & $25.9 \pm 5.6$ & $24.3 \pm 7.7$ & \\
Post-test (mean \pm SD) & & & \\
\hline
\end{tabular}

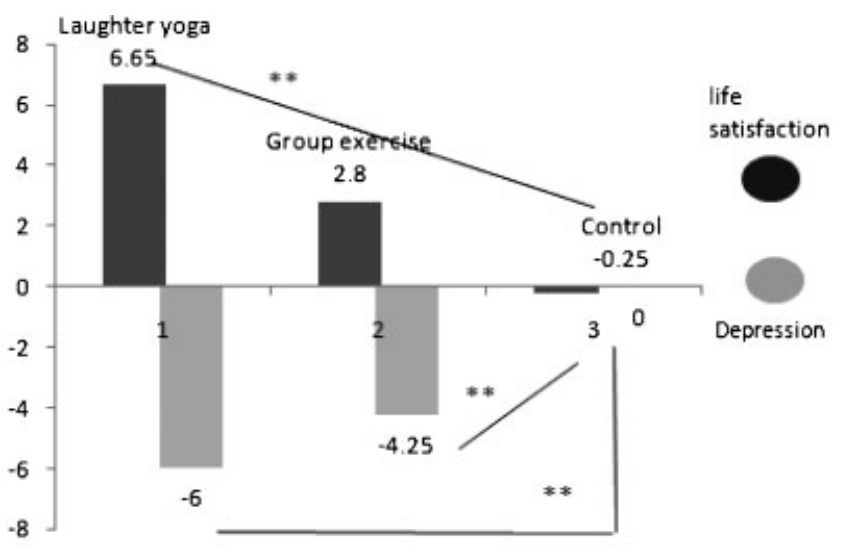

Figure 1 Changes in depression and life satisfaction scores after interventions in the study groups.

\section{Discussion}

Our aim was to provide scientific evidence for efficacy of Laughter Yoga in late life depression and our findings showed the equal efficacy of laughter therapy and exercise therapy in the improvement of depression and superior efficacy of laughter therapy over control in improving life satisfaction. So our study was the first, to our knowledge, which provided evidence for efficacy of Laughter Yoga in mental disorders.

As we noted before, there is few publications regarding Laughter Yoga in a scientific manner and no work exists which addressed the efficacy of this alternative treatment in mental disorders particularly depression. Nagendra et al. studied the effect of seven 20-30 min sessions of Laughter Yoga on 200 healthy IT professionals (both male and female) in a randomized controlled trial and found that the blood pressure and cortisol level as well as perceived level of stress was 
Laughter Yoga versus exercise in older depressed women

Table 3 Bonferroni’s Correction for comparison between study groups

\begin{tabular}{|c|c|c|c|c|c|c|c|}
\hline \multirow{2}{*}{$\begin{array}{l}\text { Dependent Variable } \\
\text { Depression score }\end{array}$} & \multirow{3}{*}{$\begin{array}{c}\text { Group (I) } \\
\text { Laughter therapy }\end{array}$} & \multirow{3}{*}{$\begin{array}{l}\text { Group (J) } \\
\text { Exercise therapy } \\
\text { Control }\end{array}$} & \multirow{3}{*}{$\begin{array}{l}\text { Mean Difference }(I-J) \\
\begin{array}{c} \\
\begin{array}{c}-1.7 \\
-6.0 *\end{array}\end{array}\end{array}$} & \multirow{3}{*}{$\begin{array}{c}\text { Std. Error } \\
1.2 \\
12\end{array}$} & \multirow{3}{*}{$\begin{array}{l}\text { Sig. } \\
0.4 \\
0.01\end{array}$} & \multicolumn{2}{|c|}{$\begin{array}{c}95 \% \\
\text { Confidence } \\
\text { Interval }\end{array}$} \\
\hline & & & & & & -4.7 & 1.2 \\
\hline & & & & & & -9.0 & -2.9 \\
\hline & Exercise therapy & Laughter therapy & 1.7 & 1.2 & 0.4 & -1.2 & 4.7 \\
\hline & & Control & $-4.2^{*}$ & 1.2 & $<0.01$ & -7.2 & -1.2 \\
\hline \multirow[t]{4}{*}{ Life satisfaction score } & Laughter therapy & Exercise therapy & 3.0 & 1.6 & 0.2 & -0.4 & 8.1 \\
\hline & & Control & $6.5^{*}$ & 1.6 & $<0.01$ & 2.6 & 11.1 \\
\hline & Exercise therapy & Laughter therapy & -3.0 & 1.6 & 0.2 & -8.1 & 0.4 \\
\hline & & Control & 3.5 & 1.6 & 0.1 & -1.2 & 7.3 \\
\hline
\end{tabular}

*Shows significant result.

Table 4 Analysis of covariance for the control of effect of pre-test scores on post-test scores

\begin{tabular}{|c|c|c|c|c|c|}
\hline & DF & Sum of square & Mean square & $F$ value & $\operatorname{Pr}>F$ \\
\hline \multicolumn{6}{|l|}{ Depression score } \\
\hline Geriatric depression scale pretest & 1 & 1523.02 & 1523.02 & 100.231 & 0.0001 \\
\hline Groups & 2 & 383.46 & 191.73 & 12.62 & 0.0001 \\
\hline \multicolumn{6}{|l|}{ Life satisfaction scale } \\
\hline Life satisfaction pretest & 1 & 806.24 & 806.24 & 31.09 & 0.0001 \\
\hline Groups & 2 & 427.07 & 213.53 & 8.23 & 0.0001 \\
\hline
\end{tabular}

significantly lower in the intervention group (Chaya et al., 2008). Results from another study showed that 15 sessions of aerobic laughter exercise significantly increased positive feelings, social identification, personal efficacy, and morale of healthy employees in the workplace (Beckman et al., 2007).

Studies on effects of humor on late life depression exist, and showed promising results; for example, a study investigated the effect of humor therapy on the depression scores and quality of life of depressive older and Alzheimer's disease patients and found that depressive patients in the humor therapy group had the highest quality of life (Walter et al., 2007). However, it may not be appropriate to compare this study with our study. Humor is something mental while laughter is something physical. This is particularly true in the context of Laughter Yoga, which its founder, Kataria believes whether one laughs with or without reason he may obtain the same benefits. Laughter Yoga is primarily an exercise rather than a mental activity; although it has mental components and affects mind. On the other hand the above-mentioned work is focused on the humor, although its output was laughter.

Humor coping was also shown to be effective in the improvement of life satisfaction (Celso et al., 2003). However, there are few findings about the effect of Laughter Yoga on life satisfaction. The life satisfaction itself has many determinants, which were shown in a meta-analysis of 245 studies in 32 countries; mental and physical health as well as personal self-efficiency are important in this regard (Veenhoven, 1991). As we mentioned previously, Beckman and colleagues showed an increased improvement of mental health as well as personal efficiency in individuals practicing Laughter Yoga (Beckman et al., 2007).

As noted before, Laughter Yoga combines yoga breathing, stretching and laughter exercise. In a systematic review, yoga itself was shown to be effective in the treatment of depressive disorder, although the same was not true for subclinical depression (Morgan and Jorm, 2008).

In our study, exercise therapy as a well-studied treatment modality, was used primarily for comparison. It improved the GDS but not LSS scores. In a review on the effect of exercise on late life depression the overall positive effects of exercise on mood was shown compared to other psychosocial or pharmacotherapeutic interventions; however, the author raised debate about the methodology of some of these studies (Blumenthal et al., 2007). Another review with a similar subject also showed promising results of the effect of exercise on depression in the elderly subjects as individuals who frequently experience losses and medical diseases (Palmer, 2005). In another study, which was done on 156 older men and women, a 16week trial of exercise also improved life satisfaction scores (Blumenthal et al., 1999). However, results from our study did not show significant improvement in life 
Key Points

- Laughter Yoga, Founded by M Kataria, is a combination of unconditioned laughter and yogic breathing and was shown to improve psychological parameters in healthy individuals.

- We evaluated its efficacy in a group of old depressed women.

- It resulted in improvement of both depression and life satisfaction and was comparable to exercise therapy.

- This study was the first, to our knowledge, that showed the efficacy of Laughter Yoga in a mental illness.

satisfaction scores among exercise therapy group. Several explanations may exist; first because the $p$ value is reaching toward significance, it may be a result of a type II error $(p=0.10)$ and another reason may be the shorter duration of our study compared to abovementioned studies. Real absence of effect of exercise on life satisfaction is less possible because other studies with larger sample size or longer duration did not show this.

Our study had several limitations; first, the sample size was not a large one and this may be responsible for the absence of significant effect of exercise on life satisfaction. Second, it is recommended that it should be better to practice Laughter Yoga in green spaces such as parks but because of socio-cultural reasons we were unable to do this. Third, lack of sufficient relevant literature limited us in the comparison of our study with others. Finally, short duration of our study prevented us from seeing the effect of longer duration of Laughter Yoga practice on our subjects.

\section{Conclusion}

In general, our study showed promising results about the effect of Laughter Yoga on the improvement of depressed mood as well as life satisfaction in elderly depressive women. However, women in this study are member of a cultural community of the Tehran; so we cannot generalize the findings to every depressed older woman all over the country as the acceptability and cultural adaptation to this exercise in more rural areas may not be as high as it is in more civilized regions. Further studies are warranted to determine the acceptability of Laughter Yoga as an exercise as well as its efficacy in larger samples including men and in comparison to psychotherapies or pharmacotherapies in late life depression.

\section{Conflicts of interest}

None declared.

\section{References}

Alexopoulos GS. 2005. Depression in the elderly. Lancet 365: 1961-1970. Beckman H, Regier N, Young J. 2007. Effect of workplace laughter groups on personal efficacy beliefs. J Prim Prev 28: 167-182.

Bennett MP, Lengacher C. 2008. Humor and laughter may influence health: III. Laughter and health outcomes. Evid Based Complement Alternat Med 5: 37-40.

Blumenthal JA, Babyak MA, Doraiswamy PM, et al. 2007. Exercise and pharmacotherapy in the treatment of major depressive disorder. Psychosom Med 69: 587-596.

Blumenthal JA, Babyak MA, Moore KA, et al. 1999. Effects of exercise training on older patients with major depression. Arch Intern Med 159: 2349-2356.

Celso BG, Ebener DJ, Burkhead EJ. 2003. Humor coping, health status, and life satisfaction among older adults residing in assisted living facilities. Aging Ment Health 7: 438-445.

Kataria M. 2005. Laugh For No Reason. Madhuri International: India

Mead GE, Morley W, Campbell P, et al. 2009. Exercise for depression. Cochrane Database Syst Rev: Issue 3. Art. No.: CD004366. DOI 10.1002/ 14651858.CD004366.pub4.

Mohammadi MR, Davidian H, Noorbala AA, et al. 2005. An epidemiological survey of psychiatric disorders in Iran. Clin Pract Epidemol Ment Health 1: 16

Morgan AJ, Jorm AF. 2008. Self-help interventions for depressive disorders and depressive symptoms: a systematic review. Ann Gen Psychiatry 7: 13.

Nagendra HR, Chaya MS, Nagarathna R, et al. 2007. Efficacy of laughter yoga on IT professionals to overcome professional stress. Laughter yoga international.

Noble RE. 2003. Drug therapy in the elderly. Metabolism 52: 27-30.

Noyes MA. 1997. Pharmacotherapy for elderly women. J Am Med Womens Assoc 52: 138-141, 158.

Palmer C. 2005. Exercise as a treatment for depression in elders. J Am Acad Nurse Pract 17: 60-606.

Timonen L, Rantanen T, Timonen TE, Sulkava R. 2002. Effects of a groupbased exercise program on the mood state of frail older women after discharge from hospital. Int J Geriatr Psychiatry 17: 1106-1111.

Veenhoven R. 1991. Questions on happiness: classical topics, modern answers, blind spots. In Subjective Well-Being: An Interdisciplinary Approach, Strack F, Argyle M, Schwarz N (eds). Pergamon Press: Great Britain; 7-26.

Walter M, Hanni B, Haug M, et al. 2007. Humour therapy in patients with late-life depression or Alzheimer's disease: a pilot study. Int $J$ Geriatr Psychiatry 22: 77-83. 